\title{
Validity and Reliability of the Scale, Role Taking in Caregivers of People with Chronic Disease, ROL
}

\section{Abstract}

Background: To determine face, content, and construct validity, and internal consistency of ROL scale.

Methods and Findings: A three-phase study was conducted. First, content analysis of the scale was carried out consulting 10 professional experts. Then, face validity was analyzed with 60 caregivers. Finally, construct validity was evaluated by performing an exploratory factor analysis (EFA) with 110 participants. Internal consistency of ROL scale was also assessed. Face validity of ROL scale reached a high acceptance index in three dimensions: role performance (0.97), role organization (0.98), and response to the role (0.98). Content validity showed coherence, clarity, and relevance of the scale. From factor analysis, three components emerged and were grouped in the same manner for varimax, quartimax, and equimax rotations. Cronbach's alpha was 0.816 , which is an acceptable overall value.

Conclusion: ROL scale makes objective the concept of role taking in family caregivers of people with chronic disease. It demonstrated to have acceptable reliability, and construct, face, and content validity to be used in the Colombian context.

\section{Keywords}

Validation Study, Caregivers, Health Transitions, Chronic Disease.

\section{Sonia Carreño Moreno', Lorena Chaparro Díaz ${ }^{2}$, Mauricio Arias-Rojas ${ }^{3}$}

1 Assistant Professor, School of Nursing Universidad Nacional de Colombia, Bogotá, Colombia

2 Associate Professor, Research Group: "Cuidado de enfermería al paciente crónico, School of Nursing, Universidad Nacional de Colombia, Bogotá, Colombia

3 Assistant Professor, School of Nursing, Universidad de Antioquia, Medellín, Colombia.

Contact information:

\section{Chaparro Díaz.}

Address: Carrera 30 No.45-03, Edif. 228 of. 301 Bogotá-Colombia, ZIP Code 111321.

Tel: 571-3165000 Ext. 17001

झ olchaparrod@unal.edu.co

\section{Introduction}

Chronic non-communicable diseases (CNCDs) represent the main cause of morbidity and mortality in the world. In developing countries, $75 \%$ of deaths are due to CNCDs [1], which shows an increasing trend owing to the epidemiological profile of these countries, especially in Latin America where this phenomenon has become a major public health issue [2-4]. 
People with CNCDs have progressive loss of functional ability, which leads to become partly or fully dependent for performing basic living activities $[5,6]$. It entails direct and ongoing supervision in clinical and home settings, and family caregivers' involvement. Usually, these caregivers are people with family bonds who, out of a sense of responsibility and commitment to the other, take over carerelated tasks [7].

Family caregivers must carry out a series of instrumental activities for which they are not prepared. It involves new challenges to take on, which bring about changes in their personal, professional, economic and social lives [8,9]. These changes comprise a transition as the family member moves from being husband, mother, father, son, or brother of a healthy person to being caregiver of a person with CNCD. For caregivers, this transition brings about stressors, relationship changes, expectations about care tasks, and new knowledge [10, 11].

A person's transition into family caregiver affects the balance of the live they have normally led, because they are faced to respond with undeveloped skills and factors that upsets a new role taking. Caregivers can adapt themselves to role shifting [12], but during transition, they might experience bewilderment, desires of leaving their caregiving tasks, loss of sense of purpose, disorientation, and disintegration of support systems, until they find a positive perspective of their tasks [13]. This eventually leads caregivers to adaptation, turning the new situation into an opportunity for continuous learning and personal satisfaction [11].

Transitions are cognitive, behavioral and interpersonal processes that must be periodically assessed. They can be based on interventions that allow role clarification, role modeling, and role rehearsal, permitting adaptation to patient and caregiver needs [11].

Each transition may or may not be healthful and is determined by outcome indicators. These indicators are related to caregiver's coping, self-confiden- ce, learning, and satisfaction acquired by exercising their caregiving role. Having healthy practices allows development of process indicators: optimum role performance (task), role organization, and making sense of the exercise of the role [14].

In order to make objective the role-taking construct in family caregivers of people with CNCD, and using Afaf Meleis's Transitions Theory as conceptual framework [11], the authors of this study proposed an instrument called Role taking in Family Caregivers of People with Chronic Disease -ROL Scale-, which is an indicator for caregiver's role-taking process.

An indicator for caregiver's role taking process is proposed based on three aspects: 1) Response to the role. Caregiver's reactions to the experience of role taking. They represent caregivers' capacity to transcend or, on the contrary, if they express negative feelings about their task, they may lose the course of it. 2) Role Organization. It indicates the distribution of caregiving tasks, activity allocation, and social support to take breaks to rest and reduce mental and physical burden. 3) Role performance. It comprises caregivers' encounter with the shock of disease diagnosis, and their capacity to adapt themselves to caregiving tasks. It includes, among other aspects, performing caregiving activities, and adjusting things at home to meet patient's needs $[11,14]$.

In order to have a valid and reliable empirical indicator for role taking in family caregivers of people with CNCD in Colombia, the present study was conducted with the objective of determining internal consistency and face, content and construct validity of ROL Scale.

\section{Method}

\section{Design}

It was a validation study conducted in three phases between February and December 2017. 


\section{Data collection instruments}

ROL Scale. This instrument was previously developed by the researchers in an earlier study [15] that involved a literature review and aimed to measure the phenomenon of role taking in family caregivers of people with CNCD. ROL Scale is a process indicator with three dimensions that correspond to role taking attributes: role performance (7 items), role organization (8 items), and response to the role (7 items). It is a Likert-type scale that consists of 22 items with five response options ranging from 1 (Never) to 5 (Always). Response scores range from 22 to 110: the higher the score, the greater the caregiver's role taking.

\section{Phases}

\section{Content Validity}

To validate content, eleven health professionals from Colombia, Chile, Mexico, Peru, and Argentina, with master's degrees and expertise in care of patients with CNCD and family participated in the study. They evaluated items' clarity, relevance, and coherence, using a three-point Likert scale. First, agreement index was established by calculating Fleiss' kappa index. Then, content validity ratio (CVR) was calculated for each item. Finally, content validity index (CVI) was calculated using Lawshe's Index modified by Tristan [16] for clarity, relevance, and coherence aspects.

\section{Face Validity}

It was assessed with 60 caregivers enrolled in the supportive outreach program "Cuidando a cuidadores" (Caring for caregivers) held by the School of Nursing. These caregivers rated the items as comprehensible, barely comprehensible, and incomprehensible. A comprehensibility index was established, ranging from 0 (utterly incomprehensible) to 1 (utterly comprehensible). Comprehensibility was assessed for each item, for the overall scale and for its dimensions.

\section{Construct Validity and Reliability}

Taking a rate of five informants per item, as recommended by Gorsuch cited by Lloret Segura [17], a sample of 110 family caregivers of people with CNCD from Bogotá city was used to assess construct validity and reliability of the scale. Inclusion criteria for participants at this stage were being family caregiver of a person with CNCD, being 18 years old or older, and having been playing a caregiving role for six months or more. The sample was drawn from family caregivers enrolled in the outreach program above mentioned in 2017. Once participants were identified and inclusion criteria was checked, research assistants explained the aims of the study, and the caregivers signed the informed consent forms. ROL scale was filled out by the participants with the help of research assistants.

Sampling adequacy was measured by Kaiser-Meyer-Olkin (KMO) test, which was 0.835; Bartlett's test of sphericity was significant $p=(0.000)$, and the measure of sampling adequacy showed values above 0.8 for all items. Once the previous tests had been conducted, it was determined that performing an exploratory factor analysis (EFA) was feasible. EFA was performed using principal components analysis method, extracting three factors, and using three rotation methods: varimax, quartimax, and equimax. Additionally, reliability was analyzed by estimating Cronbach's alpha internal consistency coefficient, with the same caregivers who participated in the construct validity process.

\section{Ethical considerations}

This study was framed within the ethical principles for conducting research involving human subjects. Participants in this study signed an informed consent form. Furthermore, approval was obtained from people in charge of the outreach program from which participants were recruited. 


\section{Results}

\section{Phase 1. Content Validity}

Fleiss' kappa index showed a strength of agreement between almost perfect agreement and substantial agreement on the three aspects the expert judges had to evaluate: almost perfect for coherence (0.85), substantial for clarity (0.67), and almost perfect for relevance (0.93).

Table 1 presents Content Validity Ratio (CVR) for each item and aspect of interest: coherence, clarity

Table 1. Proportion of expert judges who evaluated an item "positively" (CVR).

\begin{tabular}{|c|c|c|c|c|}
\hline \multirow{3}{*}{ Item } & \multicolumn{3}{|c|}{ Aspect of interest } & \multirow{3}{*}{$\begin{array}{c}\text { CVR } \\
\text { Interpretation }\end{array}$} \\
\hline & \multirow{2}{*}{$\begin{array}{c}\text { Coherence } \\
\%\end{array}$} & \multirow{2}{*}{$\begin{array}{c}\text { Clarity } \\
\%\end{array}$} & \multirow{2}{*}{$\begin{array}{c}\text { Relevance } \\
\%\end{array}$} & \\
\hline & & & & \\
\hline 1 & 100 & 100 & 100 & \multirow{22}{*}{ Acceptable } \\
\hline 2 & 100 & 100 & 100 & \\
\hline 3 & 100 & 100 & 100 & \\
\hline 4 & 80 & 60 & 90 & \\
\hline 5 & 100 & 90 & 100 & \\
\hline 6 & 90 & 70 & 100 & \\
\hline 7 & 90 & 70 & 100 & \\
\hline 8 & 100 & 90 & 100 & \\
\hline 9 & 90 & 80 & 100 & \\
\hline 10 & 80 & 70 & 100 & \\
\hline 11 & 100 & 90 & 90 & \\
\hline 12 & 90 & 90 & 80 & \\
\hline 13 & 100 & 90 & 100 & \\
\hline 14 & 100 & 90 & 100 & \\
\hline 15 & 100 & 70 & 100 & \\
\hline 16 & 100 & 70 & 100 & \\
\hline 17 & 90 & 100 & 100 & \\
\hline 18 & 90 & 80 & 100 & \\
\hline 19 & 100 & 90 & 100 & \\
\hline 20 & 100 & 90 & 100 & \\
\hline 21 & 80 & 100 & 90 & \\
\hline 22 & 100 & 100 & 100 & \\
\hline \multicolumn{5}{|c|}{ Source: study data. } \\
\hline
\end{tabular}

and relevance. An acceptable assessment from CVR is observed for all 22 items.

Table 2 presents Content Validity Index (CVI) for each aspect of interest. An acceptable assessment from CVI is observed in all three aspects.

Table 2. Content Validity Index (CVI).

\begin{tabular}{|l|c|c|}
\hline \multirow{2}{*}{ Aspect of interest } & CVI & Interpretation \\
\cline { 2 - 2 } & $\%$ & \\
\hline Coherence & 94.55 & \\
\hline Clarity & 85.91 & Acceptable \\
\hline Relevance & 97.73 & \\
\hline & & Source: study data. \\
\hline
\end{tabular}

Phase 2. Face

\section{Validity}

The following are demographic characteristics of caregivers who participated in the face validation process. (Table 3)

The participants for this stage were 60 family caregivers of people with CNCD. From the results obTable 3. Sample characteristics Phase 2.

\begin{tabular}{|l|c|}
\multicolumn{1}{c|}{ Variable } & $\%$ \\
\cline { 2 - 2 } & $\mathrm{n}=60$ \\
\hline Age & \\
\hline Standard deviation & 8.34 \\
\hline Min & 39 \\
\hline Max & 67 \\
\hline Mean & 47.56 \\
\hline Gender & \\
\hline Male & 23.33 \\
\hline Female & 76.66 \\
\hline Educational Attainment & \\
\hline Elementary School diploma & 30 \\
\hline Incomplete Elementary School & 18.33 \\
\hline High School diploma & 21.66 \\
\hline Incomplete High School & 30 \\
\hline Place of Origin & \\
\hline Bogotá & 38.33 \\
\hline Boyacá & 10 \\
\hline Cundinamarca & 51.66 \\
\hline
\end{tabular}




\begin{tabular}{|c|c|}
\hline \multirow{2}{*}{ Variable } & $\%$ \\
\hline & $n=60$ \\
\hline \multicolumn{2}{|l|}{ Marital Status } \\
\hline Single & 20 \\
\hline Married & 60 \\
\hline Non-marital cohabitation & 20 \\
\hline \multicolumn{2}{|l|}{ Occupation } \\
\hline Homemaker & 63.33 \\
\hline Employee & 23.33 \\
\hline Free-lancer & 13.33 \\
\hline \multicolumn{2}{|l|}{ Socioeconomic Status } \\
\hline 1 & 20 \\
\hline 2 & 26.66 \\
\hline 3 & 53.33 \\
\hline
\end{tabular}

Source: Research data

tained, a high comprehensibility index was evident in each dimension of the instrument: role performance (0.978), role organization (0.970), and response to the role $(0.983)$. Overall acceptance index for the instrument was 0.977. Comprehensibility of each item was above 0.9 , in all cases.

The participants had no observations or suggestions about the items in terms of comprehensibility, redundancy or missing content. The average time to fill out the scale was 10 minutes.

\section{Phase 3. Construct Validity and Reliability}

Table 4 presents demographic characteristics of the caregivers who participated in this phase.

Table 4. Sample characteristics Phase 3.

\begin{tabular}{|l|c|}
\multicolumn{1}{c|}{ Variable } & $\%$ \\
\cline { 2 - 2 } & $\mathrm{n}=110$ \\
\hline Age & \\
\hline Standard deviation & 10.419 \\
Min. & 31 \\
\hline Max. & 75 \\
\hline Mean & 58.98 \\
\hline Gender & \\
\hline Male & 15.00 \\
Female & 85.00 \\
\hline
\end{tabular}

\begin{tabular}{|l|c|}
\multicolumn{1}{|c|}{ Variable } & $\%$ \\
\cline { 2 - 2 } & $n=110$ \\
\hline Educational Attainment & \\
\hline Elementary School diploma & 3.33 \\
\hline Incomplete Elementary School & 1.67 \\
\hline High School diploma & 20.00 \\
\hline Incomplete High School & 8.33 \\
\hline Complete Technical Training & 21.67 \\
\hline Technician & 1.67 \\
\hline Bachelor's degree & 28.33 \\
\hline Postgraduate degree & 15.00 \\
\hline Place of Origin & \\
\hline Bogotá & 10 \\
\hline Bolívar & 1.67 \\
\hline Boyacá & 13.33 \\
\hline Cúcuta & 1.67 \\
\hline Cundinamarca & 65 \\
\hline Magdalena & 1.67 \\
\hline Sucre & 1.67 \\
\hline Tolima & 5.00 \\
\hline Marital Status & \\
\hline Single & 13.33 \\
\hline Married & \\
\hline Divorced & \\
\hline Widowed & \\
\hline Non-marital cohabitation & \\
\hline Occupation & \\
\hline
\end{tabular}

\section{Occupation}

Homemaker $\quad 36.67$

Employee $\quad 15.00$

Free-lancer $\quad 16.67$

$\begin{array}{ll}\text { Other } & 31.67\end{array}$

\section{Socioeconomic Status}

1

2

3

48.33

30.00

10.00

5

Source: Research data 
Table 5. Factor Analysis Rotations.

\begin{tabular}{|c|c|c|c|}
\hline \multicolumn{4}{|c|}{ Rotated component matrix ${ }^{a}$} \\
\hline \multirow{2}{*}{ ROL } & \multicolumn{3}{|c|}{ Component } \\
\hline & 1 & 2 & 3 \\
\hline \multicolumn{4}{|l|}{ Varimax } \\
\hline 1 &,- 022 &,- 238 &, 574 \\
\hline 2 & ,047 & ,040 &, 593 \\
\hline 3 &, 160 &,- 177 & ,499 \\
\hline 4 & ,297 & ,248 &, 426 \\
\hline 5 &,- 129 &,- 004 & ,780 \\
\hline 6 &,- 160 &, 005 &, 664 \\
\hline 7 &,- 171 &,- 137 & ,723 \\
\hline 8 & ,429 &, 573 &,- 006 \\
\hline 9 & ,193 & ,615 &,- 241 \\
\hline 10 & ,405 & ,682 &, 031 \\
\hline 11 &, 537 &, 546 &, 038 \\
\hline 12 & 089 &, 713 &,- 012 \\
\hline 13 & 197 &, 542 & ,218 \\
\hline 14 &,- 107 & ,606 & 101 \\
\hline 15 & 137 & 260 & 119, \\
\hline 16 & ,569 & ,302 & 009 \\
\hline 17 & ,584 & ,340 &,- 047 \\
\hline 18 & 743 & ,250 &,- 117 \\
\hline 19 & 710 & ,056 &,- 087 \\
\hline 20 & 667 & ,011 &,- 026 \\
\hline 21 & ,734 & ,234 &,- 089 \\
\hline 22 & ,832 & 117 & 015 \\
\hline \multicolumn{4}{|c|}{$\begin{array}{r}\text { Extraction Method: Principal Component Analysis. } \\
\text { Rotation Method: Varimax with Kaiser Normalization. } \\
\text { a. Rotation converged in five iterations. }\end{array}$} \\
\hline
\end{tabular}

\begin{tabular}{|c|c|c|c|}
\hline \multicolumn{4}{|c|}{ Rotated component matrix ${ }^{a}$} \\
\hline \multirow{2}{*}{ ROL } & \multicolumn{3}{|c|}{ Component } \\
\hline & 1 & 2 & 3 \\
\hline \multicolumn{4}{|l|}{ Quartimax } \\
\hline 1 &,- 243 &,- 080 &, 567 \\
\hline 2 &, 035 &,- 016 &, 595 \\
\hline 3 &,- 180 & ,108 &, 512 \\
\hline 4 & ,282 & ,265 & ,426 \\
\hline 5 &,- 011 &,- 136 & 779 \\
\hline 6 &,- 006 &,- 166 & ,662 \\
\hline 7 &,- 149 &,- 162 & ,723 \\
\hline 8 & ,614 & ,367 &,- 008 \\
\hline 9 & ,630 & ,129 &,- 245 \\
\hline 10 & ,721 & ,331 & ,029 \\
\hline 11 & ,600 & ,476 & ,038 \\
\hline 12 & ,714 & ,082 &, 003 \\
\hline 13 & ,561 & 136 & ,215 \\
\hline 14 & ,592 &,- 171 & ,095 \\
\hline 15 & ,274 & ,107 & ,118 \\
\hline 16 & ,240 & ,598 & ,006 \\
\hline 17 & ,399 &, 546 &,- 045 \\
\hline 18 &, 325 & ,713 &,- 113 \\
\hline 19 & 130 & ,701 &,- 081 \\
\hline 20 & ,081 & ,662 &,- 020 \\
\hline 21 & ,309 & ,707 &,- 084 \\
\hline 22 & ,204 & ,815 &, 021 \\
\hline \multicolumn{4}{|c|}{$\begin{array}{r}\text { Extraction Method: Principal Component Analysis } \\
\text { Rotation Method: Quartimax with Kaiser Normalization } \\
\text { a: Rotation converged in five iterations. }\end{array}$} \\
\hline
\end{tabular}

\begin{tabular}{|c|c|c|c|}
\hline \multicolumn{4}{|c|}{ Rotated component matrix ${ }^{a}$} \\
\hline \multirow{2}{*}{ ROL } & \multicolumn{3}{|c|}{ Component } \\
\hline & 1 & 2 & 3 \\
\hline \multicolumn{4}{|l|}{ Equimax } \\
\hline 1 &,- 012 &,- 237 &, 575 \\
\hline 2 &, 059 &, 041 &, 592 \\
\hline 3 & 168 &,- 177 & ,496 \\
\hline 4 &, 425 &, 242 & ,304 \\
\hline 5 &,- 126 &,- 003 & ,781 \\
\hline 6 &,- 156 & ,007 &, 664 \\
\hline 7 &,- 170 &,- 135 &, 724 \\
\hline 8 &, 440 &, 564 &,- 007 \\
\hline 9 & ,203 &, 611 &,- 241 \\
\hline 10 & ,419 &, 674 & ,031 \\
\hline 11 & &, 548 &, 036 \\
\hline 12 & & ,092 & ,713 \\
\hline 13 & ,208 &, 538 & ,218 \\
\hline 14 &,- 094 &, 608 & 103 \\
\hline 15 &, 142 & 257 & ,119 \\
\hline 16 &, 313 &, 563 & ,008 \\
\hline 17 & ,591 & ,329 &,- 049 \\
\hline 18 & ,747 &, 235 &,- 120 \\
\hline 19 & ,710 &, 043 &,- 090 \\
\hline 20 &, 667 &,- 002 &,- 029 \\
\hline 21 &, 738 &, 220 &,- 092 \\
\hline 22 &, 834 & ,101 & 011 \\
\hline \multicolumn{4}{|c|}{$\begin{array}{r}\text { Extraction Method: Principal Component Analysis } \\
\text { Rotation Method: Equimax with Kaiser Normalization } \\
\text { a: Rotation converged in five iterations. }\end{array}$} \\
\hline & & & study dada. \\
\hline
\end{tabular}

This article is available at: www.intarchmed.com and www.medbrary.com 


\section{Construct Validity}

Table 5 shows the data grouped into the three components and for each rotation method used for this study.

Component 1: items from 1 to 7.

Component 2: items from 8 to 15 .

Component 3: items from 16 to 22 .

In equimax rotation, the items are grouped in the same manner, except for item 16, which was included into Component 2.

\section{Reliability}

Internal consistency reliability, as measured by Cronbach's alpha, was 0.816, which is an acceptable overall value. Item-by-item reliability showed from acceptable to reliable indices for the three components: role performance $(0.767)$, role organization (0.835), and response to the role (0.801).

\section{Discussion}

This study describes the process of designing and validating an instrument to measure role taking in family caregivers of people with CNCD, which is conceptually and psychometrically appropriate. The results of item clustering in this study are coherent with the three dimensions conceptually proposed. Furthermore, this study established that psychometric properties for each item, each dimension, and the overall scale were acceptable to Colombian context.

Regarding conceptual development of ROL scale proposed by the researchers in a previous study [15], it was observed that the experts supported such conceptual development during the content validation phase, as their opinions were considerably high. Most of them evaluated each of the items positively; this with regard to what was proposed by Lawshe and later modified by Tristan $[16,18]$.

The results from the exploratory factor analysis of the instrument showed three components for varimax, quartimax and equimax rotations, in which the item clustering is distributed in the same manner for the three components. This confirms the role taking dimensions theoretically proposed by the researchers in their previous study [15]. These dimensions are related to the three aspects of a process indicator for caregiver's role taking proposed by the instrument: 1) response to the role, 2) role organization, and 3) role performance.

Regarding the first dimension proposed for ROL scale, response to the role, which comprises aspects such as experience and positive contribution caregivers get when caring for a person with CNCD, several authors have pointed out the importance of finding meaning when providing care for a relative and its impact on variables such as caregiving overburden, stress, anxiety, and depression. In this dimension, item 4 showed low factorial load. This item states: "I think that being a caregiver is just one of the roles I have". A reasonable explanation for this behavior may be the relationship between caregivers' occupation, which for most of the participants was homemaking, and the fact that, in Colombia, in many cases, family caregivers take over this task exclusively, and without assistance, which leaves no room for performing other roles [19-21].

Regarding role organization dimension, which refers to the way caregivers arrange and plan patient's care, it was found that this dimension is related to tree of the dimensions of the scale Quality of Life in Life Threatening Illness - Family Carer Version QOLLTI-F [22]. This scale raises issues such as the importance of caregivers' health and the time to take care of themselves, their meaning of care, and their relationship with the patient and others. The relation between the dimensions of both scales supports what some authors have suggested: the possible implications a lack of role taking has for specific aspects in caregivers' quality of life, such as physical health, social relations, financial costs, and employment [23, 24]. With regard to the performance of the item 15 "I have 
allocated the financial resources to care for my relative", it scored low. We consider that the scores obtained are a result of caregivers' socioeconomic and family context, since organization of economic resources does not depend only on caregivers and their management abilities, but also on patient's decisions, consensus among family members, socioeconomic status, and other available financial support for patient care $[25,26]$.

Regarding the dimension "role performance", which refers to the knowledge and techniques that caregivers acquire to care for the patient, it was found that all items fit well into this dimension according to varimax rotation results. Different studies exploring the experience of caring for a patient with CNCD found that learning and acquiring skills to care for the patient were among the most important needs for caregivers, from skills such as feeding, to administering high-risk medications like opioids and anticoagulants [27, 28]. As to the importance of role performance dimension, it can be inferred from different studies that, in most of the cases, the gateway to caregiving role is hospitalization, because patients are later discharged with a long list of medical instructions, for which caregivers are not prepared, but they are responsible to follow them. Therefore, their priorities focus on that basic knowledge and those skills that will ensure proper care of the patient, and then move on to other aspects of care $[24,29]$. The importance of this dimension is also present in different scales available to measure caregivers' ability to provide care to patients. For example, CUIDAR scale that measures home care competence in people with CNCD [30]; PBH-LIC: $D$ scale that focuses on caregivers practical skills in caring for people with dementia [27], and PCS scale that measures preparedness for caregiving people with CNCD [31].

Some limitations of this study include the use of convenience sampling to get subjects enrolled as well as the homogeneity of the participants included. As shown in Table 3, most of them were people with average educational attainment and middle socioeconomic status. Future researches can measure preparedness for caregiving role taking in population with lower education and socioeconomic status and living in other parts of Colombia.

Regarding sample size, this study took into account Gorsuch's recommendations [17], which indicate that five participants per item may be enough to perform an EFA. However, statistical guidelines suggest that samples from five to twenty participants per observed variable (item) are necessary for confirmatory factor analysis [32, 33]. Therefore, future researches are needed using larger samples per item in order to confirm factors found in this study.

Among the strengths, it is important first to highlight the novelty of this type of scale, as it is the only instrument on caregivers of patients with CNCD that measure their caregiving role taking. Other instruments have been developed for measuring caregiving skills, preparedness for caregiving, caregivers overburden, but not for measuring role taking. Additionally, ROL scale is grounded in Meleis' Transitions Theory [14]. Following its theory principles, ROL scale measures role taking as a process that begins with role organization, passing through the performance of tasks and ending with the results achieved by being a caregiver of a patient with CNCD.

\section{Conclusions}

ROL scale makes objective the concept of role taking in family caregivers of people with CNCD in three aspects: response to the role, role organization, and role performance. According to psychometric measurements carried out for this study, ROL scale proved to have acceptable content, face, and construct validity, as well as acceptable reliability in a sample of family caregivers of people with CNCD in Colombia. ROL scale is a tool recommended for 
health professionals to measure how family caregivers have taken their role of caring a person with CNCD.

\section{Acknowledgment}

We thank the nurses Yesica Andrea Charfuelan Laguna, Leydy Johanna Rojas Ruiz, and Fredy Alexander Yaya Otálora, who made important contributions to this study with their final degree project.

\section{References}

1. World Health Organization. Noncommunicable diseases country profiles 2014. Geneva: World Health Organization; 2014.

2. Achury DM, Castaño RHM, Gómez RLA, Guevara, Rodríguez NM. Calidad de vida de los cuidadores de pacientes con enfermedades crónicas con parcial dependencia. Investigación en enfermería: imagen y desarrollo. 2011; 13(1):27-46.

3. Barrera $\mathrm{OL}$, Blanco $\mathrm{CL}$, Figueroa $\mathrm{IP}$, Pinto $A N$, Sánchez $H B$. Habilidad de cuidadores familiares de personas con enfermedad crónica. Mirada internacional. Aquichan. 2006; 6(1): 22-33.

4. Carrillo GM, Sánchez HB, Barrera OL, Chaparro DO. The Burden of Care in Instances of Chronic Non-communicable Disease. Aquichan. 2013 Aug; 13(2):247-60.

5. Wiley JA, Rittenhouse DR, Shortell SM, Casalino LP, Ramsay $\mathrm{PP}$, Bibi S, et al. Managing chronic illness: physician practices increased the use of care management and medical home processes. Health Affairs. 2015; 34(1): 78-86.

6. Hippisley CJ, Coupland C. Diabetes treatments and risk of amputation, blindness, severe kidney failure, hyperglycaemia, and hypoglycaemia: open cohort study in primary care. BMJ. 2016; 352: i1450.

7. Carrillo González GM, Ortiz LB, Herrera BS, Carreño SP, Díaz LC. Efecto del programa de habilidad de cuidado para cuidadores familiares de niños con cáncer. Rev Colomb Cancerol. 2013; 17(4):18-26.

8. Carreño SP, Campos-de-Aldana MS, Benavides F, Niño CL, Cardona RM, et al. La habilidad de cuidado del cuidador familiar en diferentes regiones de colombia. Rev. U.D.C.A Act. \& Div. Cient. 19(2): 275-284.

9. Barragán JA, Hernández NE, Moreno CM, Barragán JA. Necesidades de cuidado de la diada cuidador-persona: expectativa de cambio en intervenciones de enfermería. Rev Cuid. 2014 Sep; 5(2):748-56.

10. Moreno CS, Palomino MP, Moral FL, Frías OA, del-Pino CR. Problemas en el proceso de adaptación a los cambios en personas cuidadoras familiares de mayores con demencia. Gac Sanit. 2016 May; 30(3):201-7.
11. Meleis, Al. Transitions theory. In Smith MC, Parker ME, editors. Nursing theories and nursing practice. Philadelphia: F.A. Davis; 2015. p. 361-380.

12. Biddle BJ. Role theory expectations, identities, and behaviors. Academic Press; 1979.

13. Meleis Al, Sawyer LM, Im EO, Hilfinger Messias DK, Schumacher K. Experiencing transitions: an emerging middle-range theory. ANS Adv Nurs Sci. 2000; 23(1):12-28.

14. Meleis Al. Transitions Theory. Middle Range and Situation Specific Theories in Nursing Resarch and practice. New York: Springer Publishing Company; 2010. p.320-410.

15. Chaparro-Díaz L, Carreño SP. Adopción del rol del cuidador familiar del paciente crónico: una herramienta para valorar la transición. Rev Investig Andin. 2018; 20(36):1-15. [in editorial process]

16. Tristán-López A. Modificación al modelo de Lawshe para el dictamen cuantitativo de la validez de contenido de un instrumento objetivo. Av en medición. Universidad Nacional de Colombia. Departamento de Psicología; 2003; 6(1):37-48.

17. Carrillo GM, Sánchez-Herrera B, Barrera-Ortiz L. Habilidad de cuidado de cuidadores familiares de niños con cáncer Caring ability of family caregivers of children with cancer. Rev salud pública. 2015; 17(3):394-403.

18. Fleiss JL. Measuring nominal scale agreement among many raters. Psychol Bull. 1971; 76(5):378-82.

19. Carreño SP, Chaparro-Díaz L. Agrupaciones de cuidadores familiares en Colombia: perfil, habilidad de cuidado y sobrecarga. Pensam Psicológico. 2017; 15(1): 87-101.

20. Torres-Pinto X, Carreño-Moreno S, Chaparro-Díaz L. Factores que influencian la habilidad y sobrecarga del cuidador familiar del enfermo crónico. Rev la Univ Ind Santander Salud. 2017; 49(2):330-338.

21. Chaparro-Díaz L, Barrera-Ortiz L, Vargas-Rosero E, CarreñoMoreno SP. Mujeres cuidadoras familiares de personas con enfermedad crónica en Colombia. Rev Cienc y Cuid. 2016; 13(1):72-86.

22. Cohen R, Leis AM, Kuhl D, Charbonneau C, Ritvo P, Ashbury FD. QOLLTI-F: measuring family carer quality of life. Palliat Med. England; 2006 Dec; 20(8):755-67.

23. Williams AM, Wang L, Kitchen P. Differential impacts of caregiving across three caregiver groups in Canada: end-of-life care, long-term care and short-term care. Health Soc Care Community. 2014 Mar; 22(2):187-96.

24. Wingham J, Frost J, Britten N, Jolly K, Greaves C, Abraham $C$, et al. Needs of caregivers in heart failure management: $A$ qualitative study. Chronic IIIn. 2015 Dec; 11(4):304-19.

25. Mayorga-Álvarez JH, Montoya-Restrepo LA, Montoya-Restrepo I, Sánchez-Herrera B, Sandoval-Salcedo NM. Metodología para analizar la carga financiera del cuidado familiar de una persona con enfermedad crónica. Rev Ciencias Biomédicas. 2015; 6(1): 96-106. 
26. Sánchez Herrera B, Gallardo Solarte K, Montoya Restrepo LA, Rojas Martínez MV, Solano Aguilar S, Vargas LD. The Financial Burden of Family Care of the Chronically III in the Colombian Andean Region. Rev Ciencias la Salud. Universidad del Rosario; 2016; 14(3):339-50.

27. Sadak T, Korpak A, Borson S. Measuring caregiver activation for health care: Validation of PBH-LCI:D. Geriatr Nurs (Minneap) [Internet]. 2015 Jul 1; 36(4):284-92. Available from: http:// dx.doi.org/10.1016/j.gerinurse.2015.03.003

28. Petty M. Supporting Caregivers in Caring: Empowered to Disempowered and Back Again. Creative nursing. 2015; 21(1): 69-74.

29. Sakakibara K, Kabayama M, Ito M. Experiences of "endless" caregiving of impaired elderly at home by family caregivers: a qualitative study. BMC Res Notes. 2015 Dec; 8:827.

30. Carrillo González GM, Sánchez Herrara B, Vargas Rosero E. Desarrollo y pruebas psicométricas del Instrumento "cuidar" versión corta para medir la competencia de cuidado en el hogar. Rev SALUD UIS; 2016; 48(2): 222-231.

31. Pucciarelli G, Savini S, Byun E, Simeone S, Barbaranelli C, Vela RJ, et al. Psychometric properties of the Caregiver Preparedness Scale in caregivers of stroke survivors. Heart Lung. 2014; 43(6):555-60

32. Bearden WO, Sharma S, Teel JE. Sample Size Effects on Chi Square and Other Statistics Used in Evaluating Causal Models. J Mark Res [Internet]. American Marketing Association; 1982; 19(4):425-30. Available from: http://www.jstor.org/ stable/3151716

33. Hoyle RH, Gottfredson NC. Sample Size Considerations in Prevention Research Applications of Multilevel Modeling and Structural Equation Modeling. Prev Sci [Internet]. 2015 Oct; 16(7):987-96. Available from: http://www.ncbi.nlm.nih.gov/ pmc/articles/PMC4207737/

Publish in International Archives of Medicine

International Archives of Medicine is an open access journal publishing articles encompassing all aspects of medical science and clinical practice. IAM is considered a megajournal with independent sections on all areas of medicine. IAM is a really international journal with authors and board members from all around the world. The journal is widely indexed and classified Q2 in category Medicine. 